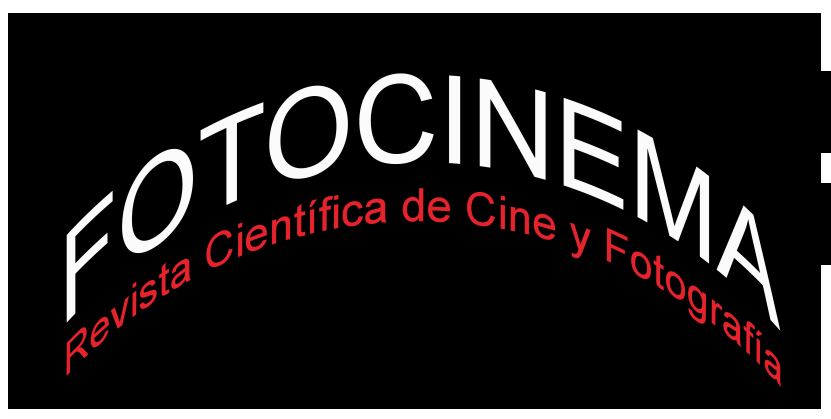

\title{
EL CUENTO TRADICIONAL EN LA MITAD DEL CIELO (1986), DE MANUEL GUTIÉRREZ ARAGÓN
}

\section{FOLK TALES IN LA MITAD DEL CIELO (1986), BY MANUEL GUTIÉRREZ ARAGÓN}

\author{
Sofía González Gómez \\ CCHS-CSIC, España \\ sofia.gonzalez@cchs.csic.es
}

\section{Resumen:}

La película La mitad del cielo (1986), de Manuel Gutiérrez Aragón (Torrelavega, Cantabria, 1942), toma como estructura la propuesta por Vladimir Propp en su análisis del cuento tradicional. El director cántabro cuenta el periplo vital de una mujer, viuda y madre, que deja atrás su aldea natal para ascender socialmente $\mathrm{y}$ fundar su propio negocio. El propósito de este artículo es analizar la cinta, compararla y reforzar esa fuente mediante la analogía con $L a$ Cenicienta. La aplicación de teoría de Propp se complementa con otras, que dotan al relato fílmico de elementos propios del cuento tradicional y de la antropología y contribuyen al desarrollo tanto de la trama como de los personajes.

\begin{abstract}
:
The film La mitad del cielo (1986), by Manuel Gutiérrez Aragón (Torrelavega, Cantabria, 1942) takes as structure the proposal of Vladimir Propp in his analysis of the folk tale. The Cantabrian director tells the life journey of a woman, widow and mother, who leaves her home village. She seeks higher social status and she aims to found her own business. The purpose of this article is to analyse the film, to compare it and to emphasise that inspiration by the analogy with Cinderella. The application of the theory of Propp can be complemented with anothers, which gives to the filmic story specific elements of the folk tales and of the Antropology. All they contribute to the evolution of the plot as well as of the characters.
\end{abstract}

Palabras clave: cine; literatura; cuento; Propp; Cenicienta; La mitad del cielo; Manuel Gutiérrez Aragón

Keywords: Cinema; Literature, Folk Tales, Propp; Cinderella, La mitad del cielo; Manuel Gutiérrez Aragón. 


\section{Manuel Gutiérrez Aragón y el cuento}

El cine de Manuel Gutiérrez Aragón se caracteriza por un bagaje literario del que es posible extraer algunas fuentes claras. Es el caso de La mitad del cielo, que se estrenó en 1986 y que fue galardonada con la Concha de Oro a la mejor película en el Festival Internacional de Cine de San Sebastián, donde se aprecia, en el desarrollo de la trama y de la evolución del personaje, una influencia de la lógica de lo heroico en general y del cuento La Cenicienta en particular.

La referencia a La Cenicienta fue señalada por primera vez en 1985. Aparece en el libro Conversaciones con Manuel Gutiérrez Aragón, de Augusto M. Torres, y en la entrevista que conforma el volumen el director cántabro reconoce que las reminiscencias al cuento infantil de la película se identifican con La Cenicienta (Torres, 1992, pp. 198-9). En 1978, Gutiérrez Aragón ya había reconocido su interés por el cuento tradicional en una entrevista con Les y Gato:

En el cuento tradicional hay unas constantes: el héroe que parte en busca de aventuras, la princesa encantada, la madrastra violenta y cruel, entonces, sobre estas estructuras, se puede construir cualquier narración antigua o moderna. Y decidí aplicarlas a mi cine. (Les y Gato, 1978, pp. 275-6)

El ensayo Cuentos de magia y conocimiento (1998), de Carlos F. Heredero, pone de relieve el carácter similar a los cuentos del cine de Gutiérrez Aragón, y la inspiración que estos han supuesto para el director. Heredero estudia Habla, mudita como un cuento-prólogo; Camada negra, Sonámbulos y El corazón del bosque, como cuentos del traidor y del héroe; Maravillas, Feroz y Malaventura, como cuento de iniciación y soledad; La noche más hermosa, como cuento astrológico; El Quijote, como cuento cervantino; Demonios en el jardín, La mitad del cielo y El rey del río, como cuentos de la Historia y de la infancia; y, por último, Cosas que dejé en La Habana como cuento de la Arcadia soñada. Se presenta en su libro, en fin, una tipología valiosa para abordar la filmografía de Manuel Gutiérrez Aragón, estableciendo puntos en común entre las películas y destacando los motivos recurrentes en su producción fílmica. 
Resulta significativo conocer que las dos últimas prácticas en la Escuela Oficial de Cine realizadas por Gutiérrez Aragón fueran Nana para dormir a un héroe y Hansel y Gretel, según apunta Heredero (1998, p. 16). Para Heredero, "estos dos trabajos nos ponen ya sobre la pista (...) de un tema (la condición del héroe) y de un recurso narrativo (la estructura de los cuentos infantiles) que después se desvelarán recurrentes y casi obsesivos en el desarrollo de su filmografía adulta” (1998, p. 16).

La teoría del cuento de Propp y otras teorías complementarias relacionadas con los cuentos y los relatos de héroes permiten establecer esquemas recurrentes en el film, que en estas páginas se desarrollarán. Como se ha adelantado, el cuento que aparece como trasfondo en la película es $L a$ Cenicienta: a través de la protagonista se establecen algunos vínculos, tanto en sus avatares personales como en sus lazos familiares. Nos hemos basado en la versión de La Cenicienta de Jacob y Wilhelm Grimm por su refinamiento con respecto a las versiones precedentes y por comprender un mayor número de concomitancias en relación a la película de Gutiérrez Aragón. El cuento está recogido en una antología al cuidado de Pedro Gálvez (1976), cuyas traducciones de los cuentos él mismo ha realizado.

\section{La estructura del cuento en La mitad del cielo}

El desarrollo de ciertos temas y la presencia de determinados personajes en la cinta de Manuel Gutiérrez Aragón pueden explicarse por la asimilación de la estructura del cuento tradicional ofrecida por Vladimir Propp. Esa estructura comprende un deseo de posesión de un bien por parte del héroe protagonista (en este caso, se trata de Rosa, como se verá con más detalle en el tercer apartado, focalizado en el estudio de la figura del héroe), que implica un desplazamiento con respecto al hogar, y en ese alejamiento opera el donante y tiene lugar un enfrentamiento con el adversario. Al final, se reconoce el valor del héroe $y$, en algunos casos, se celebra una boda. Propp define el cuento a partir de sus rasgos: 
Se puede llamar cuento maravilloso desde el punto de vista morfológico a todo desarrollo que partiendo de una fechoría (A), de una carencia (a) y pasando por las funciones intermedias culmina en el matrimonio (W) o en otras funciones utilizadas como desenlace. La función terminal puede ser la recompensa (F), la captura del objeto buscado o de un modo general la reparación del mal (K), los auxilios y la salvación durante la persecución (Rs), etc. (Propp, 1974, p. 107).

Esa sucesión de funciones puede originar secuencias:

A este desarrollo le llamamos una secuencia. Cada nueva fechoría o perjuicio, cada nueva carencia, origina una nueva secuencia. Un cuento puede comprender varias secuencias, y cuando se analiza un texto hay que determinar en primer lugar de cuántas secuencias se compone. (Propp, 1974, p. 107).

Con anterioridad al desarrollo de esas secuencias, se expone una situación inicial $(\alpha)$ en todos los cuentos. Se presenta a los personajes, en los que quedan esbozados sus rasgos y se destaca especialmente el carácter diferencial del héroe protagonista. En La mitad del cielo, esa situación a se identifica con una unidad familiar residente en una aldea, en la que tienen vacas y viven rodeados de naturaleza. La película comienza poniendo el foco en una anciana orinando, cuya micción se funde con el agua del arroyo. Molina Foix ha identificado a ese personaje con la "Madre Tierra, la Deméter rústica y fértil de la mitología” $(2003,101)$, lo que abundaría en su función de ayudante mágico de la protagonista. La anciana parece a lo largo de la cinta, que además concluye con su fallecimiento. Su bisnieta, la hija de la protagonista, hereda sus rasgos adivinatorios y su nombre, Olvido, de manera que Gutiérrez Aragón logra mediante ese paralelo de personajes una historia secundaria que aporta el contrapunto maravilloso.

Es muy temprano, y el padre ha de irse a trabajar. La madre despierta a sus tres hijas: dos de ellas se quejan por tener que madrugar, y la otra permanece en la cama, sin sueño, esperando el momento de comenzar el día. Es esta última quien colabora en las tareas de la casa y quien se encarga, a pesar de su juventud, de ordeñar las vacas. Se trata de la heroína protagonista. 
Presentadas sus características, que en el siguiente apartado abordaremos, se inicia la primera secuencia.

La primera secuencia de La mitad del cielo sucede en la aldea y comienza con un Principio de la acción contraria (C): la anciana vaticina a su nieta Rosa que, si se casa con un afilador, será desdichada. Rosa desoye la advertencia y se une en matrimonio con un afilador. Acontece una Partida ( $\uparrow)$, dado que Rosa se muda de casa de sus padres a una choza que está construyendo el propio afilador. Sus recursos son escasos, y el marido decide robar en la fábrica en la que trabaja para reunir los materiales suficientes. A esa Fechoría (A) cometida por el afilador, a la que hay que sumar dos acciones malévolas hacia la anciana (se niega a servirle agua y lima su bastón para sustraer el metal que lo adorna), le sigue un Castigo (V): es condenado a la cárcel, donde finalmente muere. En esta secuencia, Rosa se identifica con el "héroe víctima”, que sufre las malas acciones de su marido y debe afrontar un nuevo desplazamiento, embarazada y sin recursos económicos.

La segunda secuencia de la película comienza con una Nueva Partida $(\mathrm{C} \uparrow)$. Rosa llega a Madrid con su hija Olvido a casa de don Pedro, el jefe de abastos del mercado municipal, que ha quedado viudo y con un bebé recién nacido. A Rosa la contratan como ama de cría, pero una vez cumplida su función decide quedarse y emprender un negocio en Madrid, una Tarea difícil (M) para la que cuenta con la ayuda de don Pedro, en el que se funden las características del donador. En el mercado, Rosa conoce a Ramiro, un trabajador del Matadero que aprovecha el mercado para vender carne sin licencia. Ramiro actúa como un auxiliar para Rosa: es él quien logra que compre a buen precio y le da una serie de consejos con respecto al mercado. Rosa pide a don Pedro un puesto en el mercado y este, como buen donador, se lo otorga. Ramiro ayuda a Rosa, pero pronto ocurre una Persecución (Pr). Los compañeros vendedores no ven con buenos ojos la llegada de Rosa y la denuncian. Consiguen que cierren temporalmente su puesto y Rosa se enfrenta a la policía, dando como resultado que la lleven detenida a comisaría. Aparece en escena un nuevo auxiliar, Juan, un estudiante de Derecho, que intenta defender a Rosa sin éxito. Rosa vuelve a pedir ayuda a 
don Pedro (Socorro, Rs), y el donador logra que vuelva a retomar su negocio (Victoria, J).

Después de la resolución del problema en el mercado, se inicia la tercera secuencia. Introduciendo un elemento mágico a través de las palabras premonitorias de Olvido ("He soñado que venía la bisabuela"), el director informa de que la abuela, las hermanas y la madre de Rosa van a acudir a Madrid de visita. Un día, la abuela y Olvido salen a dar un paseo a las afueras. Rosa va a buscarlas y pregunta a la abuela dónde está su hija. Como una guía, la abuela le dice dónde está para conducirla a un antiguo restaurante, casi en ruinas y disponible para el alquiler. Dentro se encuentra Olvido, que ha permanecido allí como si estuviera esperando a su madre, dentro de un plan urdido con su abuela para, como auxiliares, conducirla a un nuevo reto. Así se presenta la tercera y última secuencia, en la que Rosa se enfrenta al objetivo de abrir un restaurante, gestionarlo y lograr el reconocimiento social.

Pero en La mitad del cielo la apertura del local no se presenta como una Tarea difícil (F): Gutiérrez Aragón prefiere prescindir de ello, pues probablemente haya sido posible por un crédito o por la ayuda de don Pedro, como se ha sugerido en la película. El verdadero reto será la organización de un banquete en el que tendrá como comensales a importantes cargos públicos, encabezados por don Pedro. El jefe de abastos actúa de nuevo como donador, pues reconoce que el restaurante necesita promoción y quiere organizar allí la cena para impulsar el negocio de Rosa. Finalmente, acepta y encara una Tarea difícil (F).

En la consecución de la tarea, Rosa se enfrenta a dos complicaciones. El primero es el obstáculo permanente que suponen las hermanas, torpes y vagas, que le hacen perder dinero de manera continua. El segundo es la presencia de ratas en el local, que logra eliminar con matarratas. Estas dos acciones se unen debido a la acción de Olvido, que intenta eliminar el primer obstáculo utilizando la solución del segundo: pone matarratas en la comida de las tías. Aunque las aparta y ese desplazamiento permite que Rosa y sus trabajadores preparen el banquete con eficiencia, la intoxicación de las tías 
da lugar al equívoco de que el restaurante sirve comida en mal estado. Un pretendiente de Rosa escucha a la madre informarla del estado de sus hermanas, y aprovecha el problema para que la dueña del restaurante ceda ante él y comiencen una relación, pues ahora trabaja en el Ministerio de Comercio y tiene el poder sobre las inspecciones de sanidad en los restaurantes.

El banquete resulta un éxito y Rosa logra el Reconocimiento (Q) gracias al Cumplimiento de las Tareas Difíciles (N), aunque las complicaciones no han cesado. La abuela se va de casa y emprende un retiro en el campo: parece que su ayuda ha dejado de ser necesaria; se marcha a morir, pero Olvido toma el relevo mediante la calza de los zapatos tradicionales de su abuela. Las hermanas y la madre vuelven a la aldea y se quedan Rosa y Olvido en casa. Se aprecia un cambio en la vestimenta de Rosa: ha ascendido en la escala social $\mathrm{y}$, como héroe, recibe una nueva apariencia ( $\mathrm{T}$ ), pero aún ha de solucionar la denuncia que le han puesto desde el Ministerio de Comercio por la escasa limpieza del restaurante.

Rosa pide ayuda a don Pedro, pero él le dice que no puede hacer nada porque ya está jubilado. Ha dejado de ser un donador. Sin embargo, aún logra que se celebre un banquete con altos cargos, y se simboliza en una secuencia en la que una mano pasa el trapo sobre una placa con el nombre del restaurante, "Rosa y Olvido", que ya se ha solucionado el problema higiénico. Rosa come junto a esas personalidades, vistiendo un traje lujoso y portando joyas (se incide en la función T, ya mencionada). El banquete, como en la anterior ocasión, prueba otro justificado Reconocimiento (Q) para Rosa, y poco después el restaurante acoge otro, para celebrar una boda. La película termina, siguiendo la estructura del cuento maravilloso, con una Boda (W). La originalidad de La mitad del cielo reside en que la boda no es de la heroína protagonista, sino de otro de sus pretendientes, que está enamorado de ella, y sus miradas y palabras, además de la ausencia en plano de la novia, transmiten la sensación de que el personaje que se ha casado ha sido Rosa. 


\section{Rosa, una heroína donadora}

Vladimir Propp considera al héroe como beneficiario de dones y no como distribuidor. Como ha apuntado José Manuel Pedrosa, Propp sitúa "la actividad donadora más en la órbita de los personajes auxiliares que en la del propio héroe protagonista" (Pedrosa, 2003, p. 43). En el modelo narratológico del propio Pedrosa, expuesto en La lógica de lo heroico (2003), y partiendo del sistema de dones ofrecido por Marcel Mauss en Ensayo sobre el don (1925), el héroe se caracteriza fundamentalmente por ser un donador, con el fin de que su generosidad le reporte el reconocimiento social.

Rosa protagoniza tres situaciones en las que es poseedora de un bien. En la segunda secuencia, al haber dado a luz a un bebé tiene leche materna, y por ello es contratada como ama de cría. Hay una secuencia en la que se subraya su condición de donadora: su hija llora porque tiene hambre, pero debe seguir alimentando al bebé de don Pedro porque es la función que le ha sido encomendada. Se ve entonces cómo sacrifica el bienestar de su propia hija por el trabajo. La segunda situación se circunscribe a su periplo en el mercado. Para montar su puesto, han tenido que ocupar el rincón en el que un niño huérfano se sentaba. El niño pretende vengarse de Rosa amenazándola con un cuchillo, que llega a empuñar para clavárselo. Después de pelearse, llega la policía y Rosa no solo decide no denunciarlo, sino que le da una oportunidad contratándolo como limpiador del puesto. La tercera y última situación en la que se pone de relieve a Rosa como donadora se localiza en la última secuencia: Rosa va a abrir un restaurante y ofrece contratar a Ramiro como camarero, que por un lado asciende laboralmente y por otro le proporciona un trabajo que de verdad le ilusiona.

Hay otras dos situaciones, menos significativas en el desarrollo de la trama, que se relacionan con la teoría del don. Cuando llega a la casa de Madrid, don Pedro se queja de que tiene hambre, pero es de noche, las tiendas están cerradas y en la casa solo tienen una yema y leche. Rosa prepara un arroz con leche que entusiasma a don Pedro, en una escena con claras reminiscencias sexuales, en tanto que el jefe de abastos se come el postre con ansia y placer. La segunda tiene que ver con el hecho de que Rosa mande dinero a su casa y 
compre una televisión para sus hermanas, a pesar de que, como ya se ha apuntado, supongan una lacra para ella.

Además de la generosidad, cabe apuntar otro rasgo de Rosa, que se explicaría a partir de la teoría de los cuerpos abiertos y cerrados elaborada por José Manuel Pedrosa a partir de elementos de Mijail Bajtin y de Claude LéviStrauss. Rosa es parca en palabras, no se muestra manteniendo relaciones sexuales, ingiere poquísimo alimento (en las escenas en las que come con don Pedro se señala claramente la dicotomía entre la gula de él frente al recato de ella), y sin embargo cocina muy bien. Los héroes, según Pedrosa, se caracterizan por ser de cuerpo cerrado, lo que se relaciona con su situación inicial de carencia o bien limitado (2003, p. 40). Vicente Molina Foix, por su parte, ha llamado la atención sobre la influencia de Lévi-Strauss en la película, en la que hay elementos de su teoría de la etnología culinaria "que marcan genitivamente el film" (2003, p. 105).

\section{La influencia de La Cenicienta}

Hasta ahora hemos estado identificando la estructura cuento ofrecida por Propp de manera con La mitad del cielo. Es posible concretar y establecer una fuente cuentística que ejerce de inspiración para la película: se trata de La Cenicienta.

En los dos cuentos hay una protagonista mujer que tiene dos hermanas (de sangre en la película; hermanastras en el cuento) torpes y envidiosas, que llevan vestidos mejores. En la película, se ve a las hermanas con vestidos de color azul y rojo, respectivamente, muy llamativo y que contrasta con el traje de Rosa; en el cuento, se dice que las hermanastras llevan "hermosos vestidos, perlas y piedras preciosas" (Grimm, 1999, p. 191).

Rosa, al igual que Cenicienta, madruga cada mañana:

Entonces tuvo que trabajar duramente de la mañana a la noche, levantarse temprano, traer el agua, encender el fuego, cocinar y lavar. (Grimm, 1999, p. 191). 
Estas características, en contraposición con la personalidad de las hermanas, se acentúan cuando van a visitarla a Madrid y, después de una dura jornada de trabajo, Rosa, cansada, se sienta y les pide a las hermanas que recojan la ropa tendida. Pero ellas le dicen que están peinándose: se niegan a ayudar a Rosa, a pesar de que reciben dinero suyo y están pasando una temporada en su casa.

Además de los rasgos que caracterizan a ambas protagonistas, hay una escena en La mitad del cielo que está inspirada en el siguiente fragmento del cuento:

Además, sus hermanastras la sometían a todas las mortificaciones posibles, se mofaban de ella y le tiraban los guisantes y las lentejas en las cenizas, para que tuviera que pasarse las horas recogiéndolos. (Grimm, 1999, p. 191).

En la tercera secuencia, cuando Rosa está preparando el banquete inaugural, las hermanas tiran toda la comida al suelo, en un claro arrebato motivado por la envidia, pues con anterioridad habían calificado a Rosa como "engreída". Sin embargo, Rosa es paciente y retoma la organización de la comida, que logra celebrar con la ayuda de sus auxiliares. Según Gutiérrez Aragón, esa escena "fue muy criticada en el momento del estreno" (Torres, 1992, 1999) y, para Torres supone "la apoteosis de las hermanas torpes y tontas de Cenicienta y lo que desencadena que Olvido intente envenenarlas” (1992, p. 199).

La relación entre La Cenicienta y La mitad del cielo no se mantiene en el final, y en este punto reside la modernidad de la cinta. En el cuento, Cenicienta se casa y, a través de su matrimonio, logra el reconocimiento y el ascenso en la escala social. Por el contrario, Rosa no se une en nupcias con nadie, a pesar de la dilogía visual ya comentada, y consigue ambos elementos por sus propios medios. El triunfo en el restaurante, que logró no sin antes haberse enfrentado a diversas complicaciones tanto en Madrid como en su aldea natal, supone el final de la película: Gutiérrez Aragón concluye apostando, en definitiva, por la emancipación de la mujer. De hecho, el título apunta a esa idea, como reconoce el propio director: 
La mitad del cielo es una frase de Mao. Para convencer a los chinos de que debían respetar a la mujer y considerarla, porque en la China pre-maoísta no lo estaba nada. Mao-Tse-Tung echó mano de una máxima de Confucio, que decía: "Las mujeres constituyen la mitad del cielo". Se me ocurrió utilizarla como título porque me gustaba por sí misma. Al igual que aquí se dice que la mujer es la costilla de Adán, en China se dice que es la mitad del cielo (Torres, 1992, p. 198).

\section{Conclusión}

En La mitad del cielo asistimos ante la evolución de Rosa, una mujer del norte que llegó a Madrid para labrarse una vida. La historia de la protagonista coincide, como se ha podido ver, con la estructura del cuento expuesta por Vladimir Propp, y presenta influencias de otras teorías antropológicas que complementan la película y la perfeccionan. Gutiérrez Aragón nos ofrece un retrato de una España que se encontraba en transición, y para ello se sirve de una historia particular, influida en gran medida por la del cuento La Cenicienta, que la mirada del director cántabro convierte en universal: La mitad del cielo cuenta, en última instancia, la historia de superación de una mujer convertida en la heroína de un relato fílmico.

\section{Referencias bibliográficas}

Grimm, J. y W. (1999). Cuentos (ant. y trad. de Pedro Gálvez). Madrid: Alianza Editorial.

Gutiérrez Aragón, M. (1986). La mitad del cielo. España: Luis Megino P.C.

Heredero, Carlos F. (1998). Cuentos de magia y conocimiento. El cine de Manuel Gutiérrez Aragón. Madrid, Alta Films.

Les Hernández, J. y Gato, M. (1978). El cine de autor en España. Madrid: Castellote Editor.

Molina Foix, Vicente (2003). Manuel Gutiérrez Aragón. Madrid: Cátedra.

Pedrosa, José Manuel (2003). La lógica de lo heroico: mito, épica, cuento, cine, deporte... (modelos narratológicos y teorías de la cultura). En Los mitos, los héroes. Urueña: Centro Etnográfico de Castilla y León, pp. 37-63. 
Propp, V. (1974). Morfología del cuento. Madrid: Editorial Fundamentos.

Torres, A. M. (1992). Conversaciones con Manuel Gutiérrez Aragón. Madrid: Editorial Fundamentos.

Cómo citar: González Gómez,, S. (2017). El cuento tradicional y la influencia de La Cenicienta en La mitad del cielo (1986), de Manuel Gutiérrez Aragón. Fotocinema. Revista científica de cine y fotografía, $\mathrm{n}^{0}{ }_{14}$, pp. 99-110. Disponible: http://www.revistafotocinema.com/ 